\title{
Development of System Based Code (1) Reliability Target Derivation of Structures and Components*
}

\author{
Kenichi KURISAKA**, Ryodai NAKAI**, Tai ASAYAMA** \\ and Shigeru TAKAYA** \\ **Japan Atomic Energy Agency, \\ 4002, O-arai, Ibaraki, 311-1393, Japan \\ E-mail: kurisaka.kennichi@jaea.go.jp
}

\begin{abstract}
The present paper describes a new method for determining the target value of structural reliability in the framework of the System Based Code (SBC) by considering the safety point of view. This new method utilizes analysis models of a probabilistic safety assessment (PSA), and the reliability target is derived from (1) the proposal to a quantitative safety goal that was published by the nuclear safety commission (NSC) of Japan; (2) the quantitative safety design requirements on the core damage frequency (CDF) and the containment failure frequency (CFF) that were determined in the Fast Reactor Cycle Technology Development (FaCT) project by Japan Atomic Energy Agency (JAEA). This method was applied to determine the reliability target of the structures and components which constitute the reactor cooling system in the Japan sodium-cooled fast reactor (JSFR). The risk from the reactor is shown by the sum of combination of various elements in the PSA analysis model. Those elements include dynamic failures and static failures of the structures and components, and human errors. However, the present study focuses on the sequences including the static failure, and the probability of dynamic failures and human errors in those sequences is conservatively assumed as a unity. It was confirmed that the present method combined with the PSA analysis model for internal initiating events is applicable to determine the reliability target associated with a random failure of the structures and components, and also confirmed that the method related to seismic initiating events can derive the target value of the occurrence frequency at which any of the important structures and components fails due to an earthquake.
\end{abstract}

Key words: System Based Code, Reliability Target, Safety Goal, Probabilistic Safety Assessment, Core Damage Frequency, Containment Failure Frequency, Sodium-Cooled Fast Reactor

\section{Introduction}

The SBC was advocated for the first time by the late Yasuhide Asada professor emeritus ${ }^{(1)-(3)}$. Since then, The SBC has been developed mainly in the domain of examination of structural design codes and standards for sodium-cooled fast reactor systems ${ }^{(4)(5)}$.

The objectives of SBC are as follows: to give a framework of codes and standards increased flexibility; to give a rational method for margin exchange in order to increase flexibility; to enable optimization of margins for integrity of structures and components; to evaluate integrity through identified scope from premise to decommissioning. In conventional codes and standards, individual margins are given first and then they are

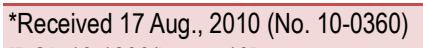
[DOI: 10.1299/jpes.5.19]

Copyright $\odot 2011$ by JSME 
accumulated so that the total margin becomes excessive. On the other hand, in the SBC, total required margin is defined first and then it is distributed to each individual requirement in a rational manner.

There are two domains in the codes and standards of nuclear installations. One is the structural design/evaluation, the other is the safety design/evaluation. In a process of developing the SBC, it became particularly necessary to harmonize the structural reliability evaluation and the PSA. It is an urgent issue to develop a technical method for determining an adequate value of the reliability target to utilize SBC concept. It is one idea to utilize the PSA. In such a case, it is still required to develop a method to connect the reliability target with a risk-information obtained from the PSA.

The objective of the present research is to propose a method for determining the reliability target of structures and components in the SBC. The present research addresses (1) summarization of a basic information for determining the reliability target in terms of safety, (2) an approach to derivation of the reliability target by disintegrating the basic information with PSA analysis models, and (3) examination of applicability of this approach to the JSFR system through a preliminary application with respect to derivation of the reliability target based on a level-1 PSA for internal events during power operation and for seismic events.

\section{Basic Information for Determining the Reliability Target in Terms of Safety}

The NSC of Japan recognized that establishment of safety goals which indicate an acceptable level of the risk and applying the PSA technology to the safety regulatory/management activities can achieve more effective safety assurance activities and further improvement in safety. The NSC of Japan then established the special committee on safety goals in order to execute the research and deliberations on safety goals from the broad point of view in September 2000.

According to the interim report of the special committee ${ }^{(6)}$, the safety goals expressed with a metric of the risk to the public are important and objective when indicating the level of safety because it is preferable to be common to the risk accompanied with various activities which have potential to cause the health damage. In the interim report, the proposal on safety goals is made of the following configurations.

口 Proposal to Qualitative Goal

The possibility of health damage to the public by emission of radiation or release of radioactive materials accompanied with activities for utilization of nuclear energy should not meaningfully increase the risk of health damage to the public in daily life.

口 Proposal to Quantitative Goal

There are two risk indices. One is the mean value of acute fatality risk by radiation exposure resulting from an accident of a nuclear installation to individuals of the public, who live in the vicinity of the site boundary of the nuclear installation. The other is the mean value of fatality risk by cancer caused by radiation exposure resulting from an accident of a nuclear installation to individuals of the public, who live in the area but some distance from the nuclear installation. Both indices should not exceed the probability of about $1 \times 10^{-6}$ per year.

The JAEA established the development targets and design requirements in the FaCT project ${ }^{(7)}$. The development target in safety is described as follows: ensuring a safety level equivalent to future light water reactors (LWRs) and related fuel cycle system. This safety development target is common to a fast reactor system and its relevant fuel cycle systems. In order to achieve this safety development target, three design requirements are settled. One of them is a requirement to reach "risk target": i.e., the CDF should not exceed $10^{-5}$ site-year considering multiple units in a site, and the frequency of loss of containment function in core damage conditions (i.e., CFF) should not exceed $10^{-6} /$ site-year. 
The "risk target" aims at controlling the level of risk that is represented by the occurrence frequency and consequences within an acceptable range, and also aims at providing justification for the achievement of $10^{-6} /$ year or less annual fatality risk to public individuals per site due to loss of containment function during core damage arising from abnormal occurrences, even if nobody takes offsite emergency response against a potential severe accident associated with the introduction of the FBR cycle.

If we assume ten reactor units in a site and if core damage accidents and loss of containment function in core damage conditions take place independently among their units, the requirements for a single reactor unit is described as follows: the CDF should not exceed $10^{-6} /$ reactor-year (/ry), and the CFF should not exceed $10^{-7} /$ ry $^{(7)}$.

\section{Reliability Target Derivation by Using PSA Analysis Models}

\subsection{Basic concept}

The reliability of structures and components is an input of the PSA, and a quantification result of the PSA is compared to the safety goals or safety design requirements in the FaCT project. Based on this relationship, the PSA is utilized for deriving the reliability target of structures and components by following the steps shown below.

Step 1: Identify a group of structures and components such as systems or trains, loss of function of which have the same effect on the PSA analysis model.

Step 2: Define the reliability parameter of the identified groups as the probability or frequency of loss of their functions.

Step 3: Assign some numerical values to the reliability parameter of the groups.

Step 4: Determine some analysis cases expressed with combination of the assigned values.

Step 5: Compute the index given the goal or requirement (e.g., CDF) for each case with a PSA analysis model.

Step 6: Select cases, in which the computed index value reaches the goal or requirement, to provide combinations of acceptable level in the reliability parameter of the groups of structures and components.

Step 7: Determine a suitable case for the reliability target among from those cases.

In surveying candidates of the reliability target of the structures and components following the above steps, it is not efficient to conduct a calculation of the risk index (e.g., the fatality risk to the public individuals) by taking them into account all the radioactive material release sources including the reactor core and the others and all the initiating events including internal and external ones at the same time because there are too many parameters to be surveyed.

It is preferable to distribute the goals or requirements in details to some extent before applying the above steps by considering how the risk should be distributed by the release source of the radioactive material, the type of initiating events and the plant operating state from the viewpoint of the reactor safety design.

Figure 1 shows a concept of how to distribute goals on the risk index; e.g., the fatality risk to the public individuals, $\mathrm{CDF}, \mathrm{CFF}$.

\subsection{Distribution by release source of radioactive material}

Significant amount of radioactive materials exist in a new and spent fuel treatment systems except the reactor core. Those systems are not located in the containment with leak tightness. If a lot of fuel elements containing radioactive materials in those systems get damaged and melted at the same time, a consequence comparative to the severe core damage might be given to the vicinity of the facility. On the other hand, we believe that those systems can prevent such a severe fuel damage event at a high reliability compared to the reactor core. As a result, those systems can restrict the risk to the public individuals sufficiently small compared to the reactor core. Based on this belief, it is one idea to 
propose that the annual occurrence frequency of severe fuel damage except the reactor core per site is restricted sufficiently small compared to the annual fatality risk of $\sim 10^{-6}$ to the public individuals at the vicinity shown in the quantitative safety goal.

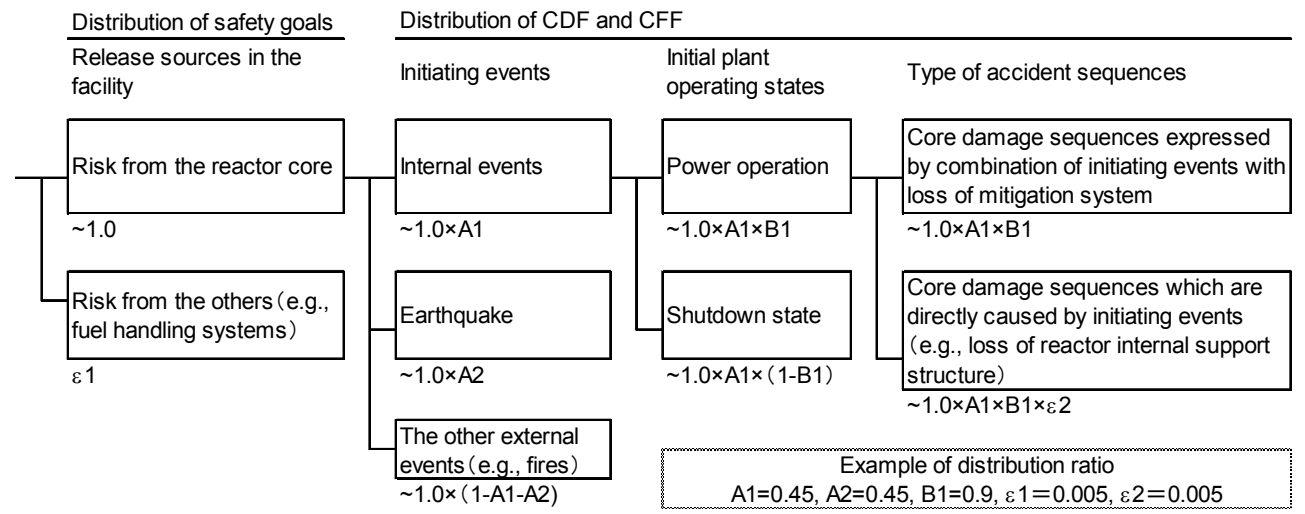

Fig. 1 Concept of how to distribute goals on the risk index

\subsection{Distribution by PSA Scope in Case of Release from Reactor}

Different types of input parameter, analysis model and method are required in estimation of the CDF and CFF depending on the PSA scope, which is the type of initiating events (i.e., internal events and external events) and the initial plant operating state (i.e., power operation and shut down) at the initiating event. Some reliability parameters may become a common input to different PSA scopes. However, if we allocate the target value of the CDF and CFF for each PSA scope, the scope of a PSA analysis model to be treated in Section 3.1 at one time becomes small, and it becomes easy to understand the PSA analysis model in a deriving process of the reliability target of the structures and components.

Contribution of the external events to the risk should be restricted smaller than that of the internal events. This is because the basic principle to secure safety is to select the site condition to avoid an external hazard as much as possible. On one hand, it is impossible to find the site condition where an earthquake is completely eliminated in Japan. If we pursue the risk from the earthquake much smaller than the risk from the internal events, it may result in an irrational system design. The present study proposes that the target values of $\mathrm{CDF}$ and CFF induced from the internal events and from the earthquake are assigned $\sim 4 \%$ of the total target value for each, and that the target value for the other external events (e.g., fire) becomes $\sim 10 \%$.

Next we describe the risk comparison between during power operation and in a shutdown state. According to the past PSA study on LWRs ${ }^{(8)}$, the risk during shutdown state is not negligible compared to that during power operation. The present study assumed that the CDF and CFF per unit time in a shutdown state are almost equal to those during power operation. Figure 1 shows a proposal to distribution of the target level of the CDF and CFF under this assumption with taking into account the scheduled reactor operating factor of $\sim 90 \%$.

\subsection{Further Distribution by Focusing on a Single Failure Sequence}

After the PSA scope is specified in the previous section, the reliability target of the structures and components is derived by following the steps shown in Section 3.1. The severe core damage or loss of containment function is represented as sets of mutually exclusive accident sequences, which are developed in the event tree of the PSA. In those sequences, there can be an accident sequence consisting of a single failure of the structures and components that results in the severe core damage and loss of containment function by itself; e.g., loss of reactor internal support structure. As a first trial, the present study proposed a level of the reliability target for the reactor internal support structure small 
enough compared to the target level of the CFF within the PSA scope of the internal events during power operation. The corresponding target level of the CFF becomes $0.45 \mathrm{x} 0.9 \mathrm{x}$ $10^{-7} /$ ry. In this case, if we assume a fraction small enough of 0.005 , the proposed reliability target becomes $\sim 2 \times 10^{-10} /$ ry.

\section{Application of the PSA Analysis Model of Internal Events during Power Operation}

JAEA implemented the preliminary level-1 PSA of the JSFR in the second phase of the feasibility study on commercialized fast reactor cycle systems ${ }^{(9)}$. The analysis models applied to the present study are based on this level-1 PSA and a part of the models was modified.

\subsection{Selection and Classification of Structures and Components}

Figure 2 shows the reactor heat transport system and the decay heat removal system (DHRS) in the JSFR. The static structures and components required for maintaining the sodium cooling circuit in these systems were selected for the present study: i.e.,

ㅁ Primary coolant boundary,

ㅁ Secondary coolant boundary in the secondary heat transport system (SHTS),

口 Secondary coolant boundary in the primary reactor auxiliary cooling system (PRACS),

․ Secondary coolant boundary in the direct reactor auxiliary cooling system (DRACS), and

口 Guard vessels, which envelope the reactor vessel and the primary heat transport system (PHTS) pump that is integrated into the intermediate heat exchanger (IHX); guard pipes, which envelope the PHTS pipes.

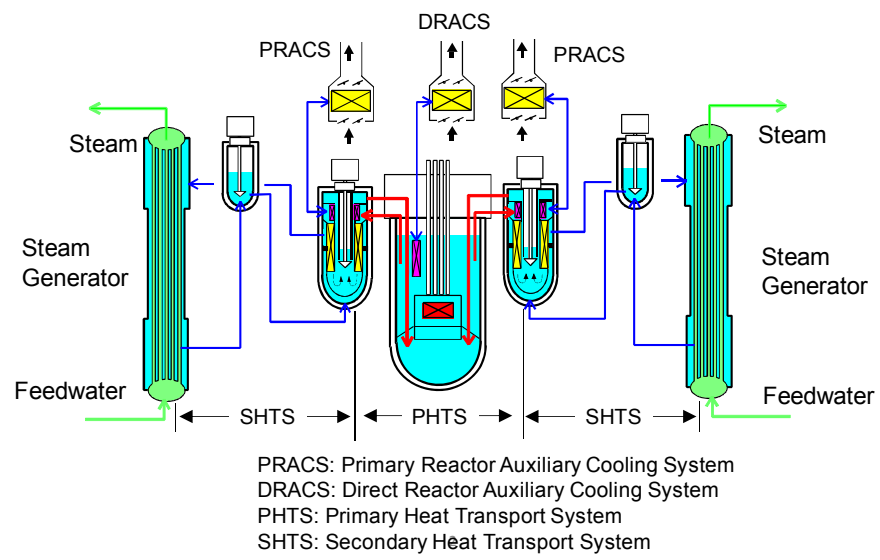

Fig. 2 Outline of the reactor heat transport system and decay heat removal system in JSFR

The failure of coolant boundaries among the selected structures and components becomes initiating events. When those initiating events take place during power operation, the JSFR secures the reactor core integrity owing to the three mitigation functions; i.e., reactor shutdown, maintaining the reactor liquid level, which is defined as maintaining the heat transfer path required for decay heat removal, and the decay heat removal. Table 1 shows a result that those initiating events were classified by considering similarity in the mitigation functions required upon those events.

On one hand, the failure of the selected structures and components also becomes loss of the mitigation functions. By reviewing the system event tree models developed in the preliminary level-1 PSA, classification of those failure was performed. Figure 3 shows an example of the system event tree to identify the sequence resulting in failure of reactor shutdown, which is called anticipated transient without scram (ATWS). The mitigation system required for reactor shutdown includes generation of reactor trip signals, actuation of the self-actuated shutdown system (SASS), and insertion of the reactor control rods. It is 
obvious that a failure of the sodium coolant boundary does not cause loss of this mitigation system.

Table 1 Classification of sodium-coolant boundary failures from the view point of similarity in response of the mitigation functions

\begin{tabular}{|c|c|c|c|c|c|c|}
\hline \multirow{2}{*}{\multicolumn{4}{|c|}{ Initiating event candidates }} & \multicolumn{3}{|c|}{ Response of the mitigation functions } \\
\hline & & & & $\begin{array}{c}\text { Reactor } \\
\text { shutdown }\end{array}$ & $\begin{array}{l}\text { Maintaining the } \\
\text { reactor liquid level }\end{array}$ & $\begin{array}{c}\text { Decay heat } \\
\text { removal }\end{array}$ \\
\hline \multicolumn{4}{|c|}{ Primary coolant boundary failure of reactor vessel below the emergency sodium level (EsL) } & RS1 & ML1 & DH1 \\
\hline \multicolumn{4}{|c|}{ Primary coolant boundary failure of reactor vessel above EsL } & RS1 & ML2 & DH1 \\
\hline \multicolumn{4}{|c|}{ Primary coolant boundary failure in the PHTS loop except interface with secondary coolant } & RS1 & ML2 & $\mathrm{DH} 2$ \\
\hline \multicolumn{4}{|c|}{ Secondary coolant boundary failure in the SHTS } & RS2 & ML3 & DH1 \\
\hline \multicolumn{4}{|c|}{ Secondary coolant boundary failure in the PRACS } & RS3 & ML3 & $\mathrm{DH} 2$ \\
\hline \multicolumn{4}{|c|}{ Secondary coolant boundary failure in the DRACS } & RS3 & ML3 & DH3 \\
\hline & $\begin{array}{l}\text { This can cause abnormality in the PHTS flow behavior. } \\
\text { This can cause loss of flow in the SHTS loop. }\end{array}$ & ML1 & \multicolumn{4}{|c|}{$\begin{array}{l}\text { This can cause core damage unless the reactor guard vessel maintains its } \\
\text { integrity. }\end{array}$} \\
\hline & $\begin{array}{l}\text { The core integrity is secured even if the reactor does not } \\
\text { shut down since there is no affect on reactor cooling } \\
\text { function by means of the main heat transport systems. }\end{array}$ & ML2 & \multicolumn{4}{|c|}{$\begin{array}{l}\text { Even if the double-wall boundary failure takes place, the reactor liquid level is } \\
\text { maintained above EsL due to the other mitigation system such as isolation of } \\
\text { the reactor and pump cover gas. }\end{array}$} \\
\hline PHT & : Primary heat transport system & ML3 & \multicolumn{4}{|c|}{ This event does not affect the reactor liquid level. } \\
\hline SHTs & Secondary heat transport system & DH1 & \multicolumn{4}{|c|}{ All the DHRS (i.e., PRACS and DRACS) can be expected. } \\
\hline PRA & CS: Primary reactor auxiliary cooling system & DH2 & \multicolumn{4}{|c|}{ Decay heat removal by the failed PRACS train cannot be expected. } \\
\hline DRA & CS: Direct reactor auxiliary cooling sy stem & DH3 & \multicolumn{4}{|c|}{ Decay heat removal by the failed DRACS cannot be expected. } \\
\hline
\end{tabular}

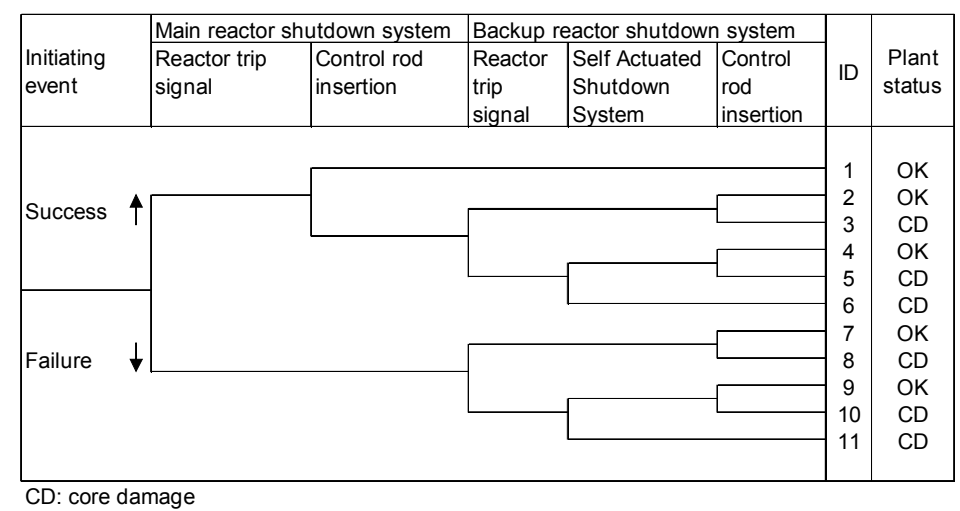

Fig. 3 An example of system event trees to identify accident sequences resulting in failure of reactor shutdown

Guard vessels, guard pipes and enclosures do not appear in Table 1. This is because these are mitigation systems to receive the leaked sodium when the sodium coolant boundary fails and the failure of this mitigation system does not cause automatic interruption of a reactor power operation, then such failure was not regarded as an initiating event in the preliminary level-1 PSA.

Figures 4 and 5 show examples of the system event tree to identify the sequence resulting in loss of the reactor liquid level (LORL) required for the decay heat removal. The mitigation system required for maintaining the reactor liquid level includes active and passive systems. The selected structures and components corresponding to these systems are as follows:

Reactor guard vessel represented in the heading "A", " $\mathrm{H}$ ", "N",

口 IHX guard vessel and guard pipes including pipes to the isolation valve in the sampling line represented in the heading "A", "H",

口 Reactor vessel below the emergency sodium level (EsL) represented in the heading " $C$ ",

$\boldsymbol{\square}$ Primary coolant boundary in the PHTS except the interface with the secondary coolant represented in the heading " $\mathrm{D}$ ", and

口 Secondary coolant boundary in the DRACS represented in the heading "M". 


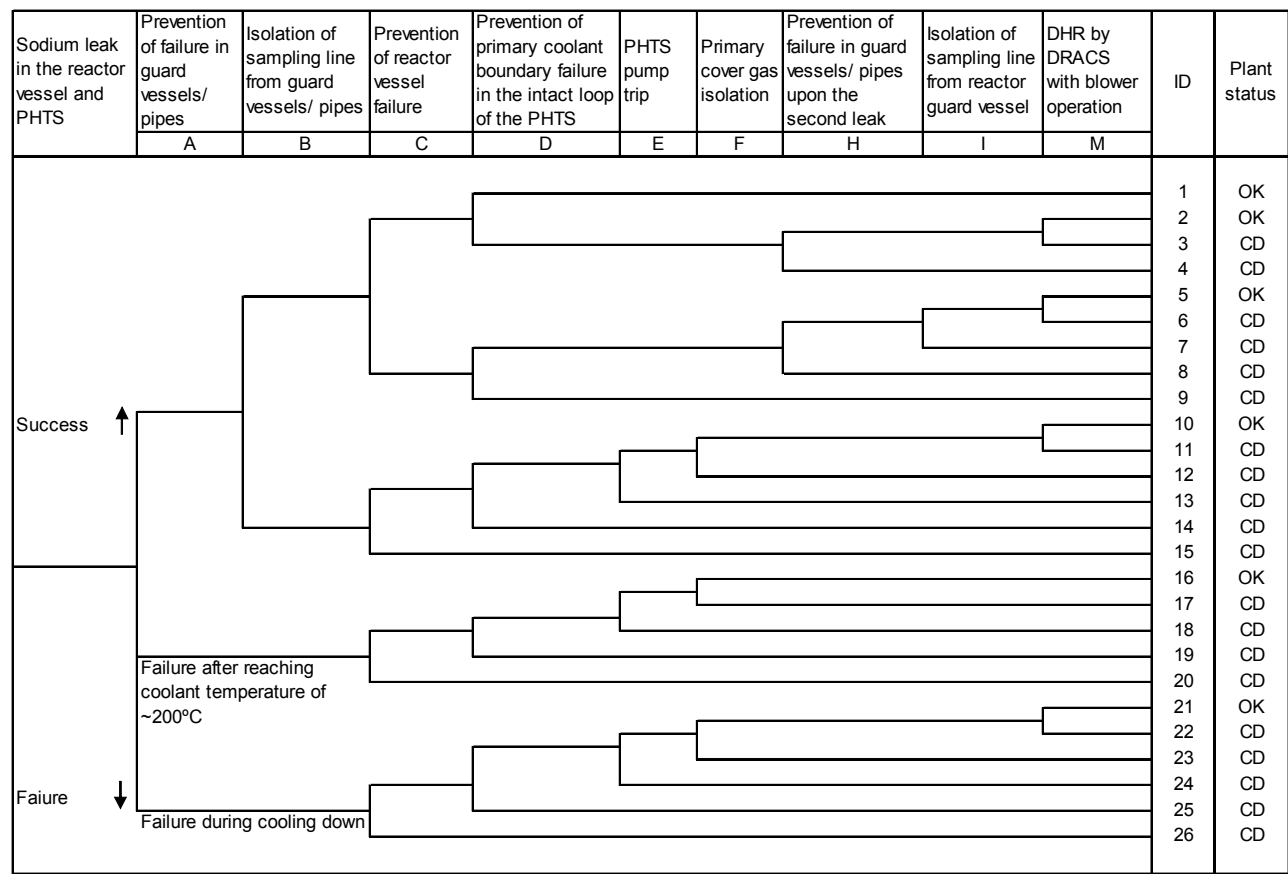

Fig. 4 An example of system event trees to identify accident sequences resulting in failure of maintaining the reactor liquid level

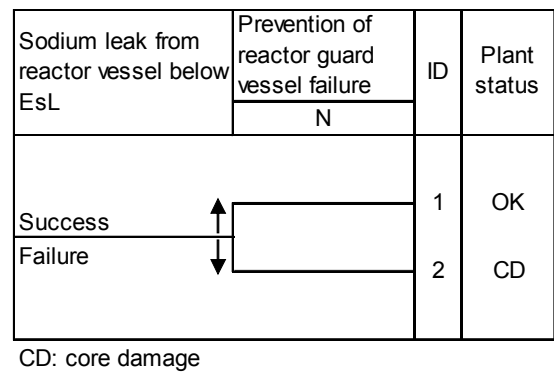

Fig. 5 An example of system event trees to identify accident sequences resulting in failure of maintaining the reactor liquid level from the reactor vessel failure blow EsL

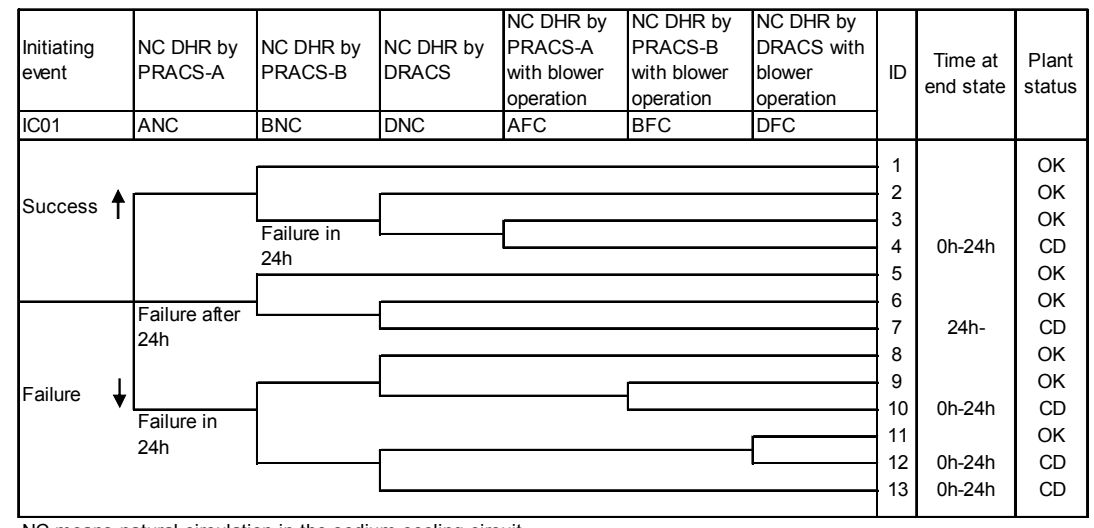

NC means natural circulation in the sodium cooling circuit.

DHR: decay heat removal

$\mathrm{CD}$ : core damage

Fig. 6 An example of system event trees to identify accident sequences resulting in loss of decay heat removal

Figure 6 shows an example of the system event tree to identify the sequence resulting in protected loss of heat sink (PLOHS). The heading events "ANC" and "BNC" in the event 
tree diagram represent heat removal by a natural circulation of sodium and a natural air flow at the air cooler in the PRACS. The heading events "AFC" and "BFC" represent heat removal by a natural circulation of sodium and a forced air draft with a blower in the PRACS. The failure of these heading events includes loss of system functions: i.e., the secondary coolant boundary in the PRACS, and the primary coolant boundary in the PHTS. In addition, the heading "DNC" represents a decay heat removal by a natural air flow in the DRACS and the heading "DFC" represents a decay heat removal by a forced air draft in the DRACS. The failure of these heading events includes the failure of the secondary coolant boundary in the DRACS.

Table 2 Reliability parameters applied in the PSA and the simplified reliability parameter for the events considered in this study

\begin{tabular}{|c|c|c|c|}
\hline Events considered in this study & $\begin{array}{l}\text { Reliability par } \\
\text { the PSA }\end{array}$ & ers applied in & $\begin{array}{l}\text { Simplified } \\
\text { reliability } \\
\text { parameter }\end{array}$ \\
\hline Primary coolant boundary failure of reactor ves sel below Es L & \multirow{6}{*}{$\begin{array}{l}\text { Annual } \\
\text { occurrence } \\
\text { frequency in } \\
\text { power } \\
\text { operation }\end{array}$} & \multirow{8}{*}{$\begin{array}{l}\text { Failure rate } \\
\text { in mission } \\
\text { time period } \\
\text { for decay } \\
\text { heat } \\
\text { removal }\end{array}$} & \multirow{8}{*}{$\begin{array}{l}\text { Occurrence } \\
\text { rate of the } \\
\text { event under } \\
\text { the condition } \\
\text { in contact } \\
\text { with the } \\
\text { sodium }\end{array}$} \\
\hline Primary coolant boundary failure of reactor vessel above EsL & & & \\
\hline $\begin{array}{l}\text { Primary coolant boundary failure in the PHTS loop except } \\
\text { interface with secondary coolant }\end{array}$ & & & \\
\hline Secondary coolant boundary failure in the SHTS & & & \\
\hline Secondary coolant boundary failure in the PRACS & & & \\
\hline Secondary coolant boundary failure in the DRACS & & & \\
\hline Reactor guard vessel failure & \multirow{2}{*}{$\begin{array}{l}\text { Failure rate in } \\
\text { standby state }\end{array}$} & & \\
\hline Failures of IHX guard vessels or guard pipes & & & \\
\hline
\end{tabular}

EsL: Emergency sodium level

As a result of the above consideration, failure events in groups of the selected structures and components are listed in Table 2 . The reliability parameters of those groups, which are defined in the PSA analysis model, are also summarized in Table 2. In general, it is assumed that the probability of a random failure is in proportion to time; i.e., its occurrence rate has a constant value with time. In the preliminary level-1 PSA, two more assumptions were taken into account. One is that there is no difference in the failure probability value per unit time between during power operation and in a shutdown state. The other is that there is a difference in the failure probability per unit time of guard vessels and guard pipes between before and after receiving the leaked sodium, and the failure probability per unit time before receiving it is one tenth of that after receiving it. If these assumptions are taken into account, the reliability parameters to be determined in the PSA analysis model are reduced as the simplified reliability parameter indicated in Table 2.

In other words, the target level of the simplified reliability parameters shown in Table 2 can be obtained by combining the level-1 PSA model of the JSFR with the target level of the CDF and/or CFF. Primarily based on the consideration in Table 1, the following sections describe the reliability target derivation with focusing on the LORL and PLOHS sequences among the core damage sequences.

\subsection{Probability of Dynamic Failures and Human Errors}

In the PSA analysis model, it is common to consider dynamic functions of components and operator actions as well as static function in the structures and components selected in the present study. However, all of them are not always treated in the SBC. At the present time, the SBC does not intend to treat dynamic functions of components and operator actions in its scope. It is preferable to derive the reliability target of the structures and components that are treated in the SBC independent from the estimation results of the reliability parameter, the level of which would be controlled by codes, standards, guides, etc. except the SBC. The present study takes a simple and the most conservative manner as a first trial, where the probability of dynamic failures and human errors is assumed equal to unity. In the specific case where the failure of mitigation system is represented with the 
combination of only dynamic failures and/or human errors, subsequently the occurrence frequency of the initiating event indicates the CDF or CFF. The corresponding accident sequences are excluded because the present study does not aim at deriving the reliability target of such dynamic functions associated with dynamic components and human actions. In the PLOHS sequences, there are initiating events due to dynamic failures or to human errors. Since the occurrence frequency of initiating events has no theoretical upper bound, this type of initiating events is also excluded because of the same reason as the specific case.

As a result of application to the LORL event tree shown in Fig. 4, the sequences 10 through 15 were excluded and the occurrence frequency of the sequences 2,5 to 6,16 to 17 , 21 to 23 was regarded as zero. In the same way, the PLOHS event tree shown in Fig. 6 was simplified into Fig. 7. Regarding the PLOHS sequence that takes place after $24 \mathrm{~h}$ in Fig. 6 , the success criterion of decay heat removal is success in at least one train among the three trains of the decay heat removal system in a natural circulation operation combined with a natural air flow at the heat sink. On the other hand, only two trains of the decay heat removal system are taken into account as shown in Fig. 7. Comparing the latter with the former, it should be noted that the latter might lead to excessively high level of the reliability target for the structures and components in the decay heat removal system, although the latter provides us a simple and robust logic to derive the reliability target.

\begin{tabular}{|c|c|c|c|c|c|c|c|c|c|}
\hline $\begin{array}{l}\text { Coolant boundary } \\
\text { failure in one loop } \\
\text { of the PHTS and } \\
\text { PRACS }\end{array}$ & $\begin{array}{l}\text { Prevention of } \\
\text { coolant boundary } \\
\text { failure in intact } \\
\text { loop of the PHTS } \\
\text { and PRACS }\end{array}$ & $\begin{array}{l}\text { Prevention of } \\
\text { coolant } \\
\text { boundary } \\
\text { failure in the } \\
\text { DRACS }\end{array}$ & \multirow[t]{2}{*}{ ID } & \multirow[t]{2}{*}{$\begin{array}{l}\text { Plant } \\
\text { status }\end{array}$} & \begin{tabular}{|l} 
Coolant \\
boundary \\
failure in \\
the \\
DRACS \\
\end{tabular} & $\begin{array}{l}\text { Prevention of } \\
\text { coolant boundary } \\
\text { failure in loop-A of } \\
\text { the PHTS and } \\
\text { PRACS }\end{array}$ & $\begin{array}{l}\text { Prevention of } \\
\text { coolant boundary } \\
\text { failure in loop-B of } \\
\text { the PHTS and } \\
\text { PRACS }\end{array}$ & \multirow[t]{2}{*}{ ID } & \multirow[t]{2}{*}{$\begin{array}{l}\text { Plant } \\
\text { status }\end{array}$} \\
\hline 11 & A & B & & & 12 & C & D & & \\
\hline Success & & & 1 & & Success 1 & & & 1 & OK \\
\hline Failure & & & $\begin{array}{l}2 \\
3\end{array}$ & $\begin{array}{l}C D \\
C D\end{array}$ & Failure & & & $\begin{array}{l}2 \\
3\end{array}$ & $\begin{array}{l}C D \\
C D\end{array}$ \\
\hline
\end{tabular}

Fig. 7 Simplified event trees of decay heat removal to be applied for the examination of the reliability target

\subsection{Derivation of the Target LORL and PLOHS Frequencies}

According to Section 3.3 and Fig.1, the target values for the CDF and CFF due to internal initiating events in power operation would become $\sim 0.9 \times 4.5 \times 10^{-7} / \mathrm{ry}$ and $\sim 0.9 \times 4.5 \times 10^{-8} /$ ry respectively. The LORL and PLOHS sequences resulting in core damage also become loss of containment function with a conditional probability of unity. On the other hand, the ATWS sequences resulting in core damage would not progress to loss of containment function at a high conditional probability owing to the safety design features aiming at in-vessel retention. By taking this into account, we neglected a contribution of the ATWS sequences to the CFF, and the target value for the CFF was divided equally into the LORL and PLOHS events. The target LORL and PLOHS frequencies became $\sim 1 / 2 \times 0.9 \times 4.5 \times 10^{-8} / \mathrm{ry}$ for each. In addition, as described in Section 4.2 , a contribution of dynamic failures and human errors to the LORL and PLOHS frequencies was eliminated from the scope of the present study, and the initiating events contain only the boundary failures of the reactor primary and secondary coolant. By assuming that these have a half contribution, the target LORL and PLOHS frequencies due to the internal events related to those boundary failures in power operation were determined equal to or less than $1 \times 10^{-8} / \mathrm{ry}$ for each that was calculated as $1 / 2 \times 1 / 2 \times 0.9 \times 4.5 \times 10^{-8} /$ ry.

\subsection{Reliability Parameter Survey Aiming at the Target}

In order to survey the reliability parameter sets that reach the target LORL and PLOHS frequencies, Steps 3 to 7 described in section 3.1 were performed in an iterative way shown in Fig. 8. The reliability parameters assumed in calculation of the LORL frequency and the 
calculation results are shown in Table 3. The Fussell-Vesely importance measure ${ }^{(10)}$ to the LORL frequency, which indicates a contribution ratio of each reliability parameter to the LORL frequency, was also calculated as shown in Table 3. While the calculated LORL frequency for the initial case is higher than the target of $1 \times 10^{-8} / \mathrm{ry}$, the frequency for cases 1 and 2 are approaching the target in order, then the frequencies for cases 3 and 4 reach the target. Therefore, the reliability parameter values for cases 3 and 4 in Table 3 become candidates of the reliability target for the structures and components so as to suppress the LORL frequency not higher than $1 \times 10^{-8} /$ ry. The difference between cases 3 and 4 appears in a distribution ratio of the reliability target between the primary coolant boundary and the guard vessels/pipes in the PHTS. It is possible to derive other candidates of the reliability target having a different distribution ratio.

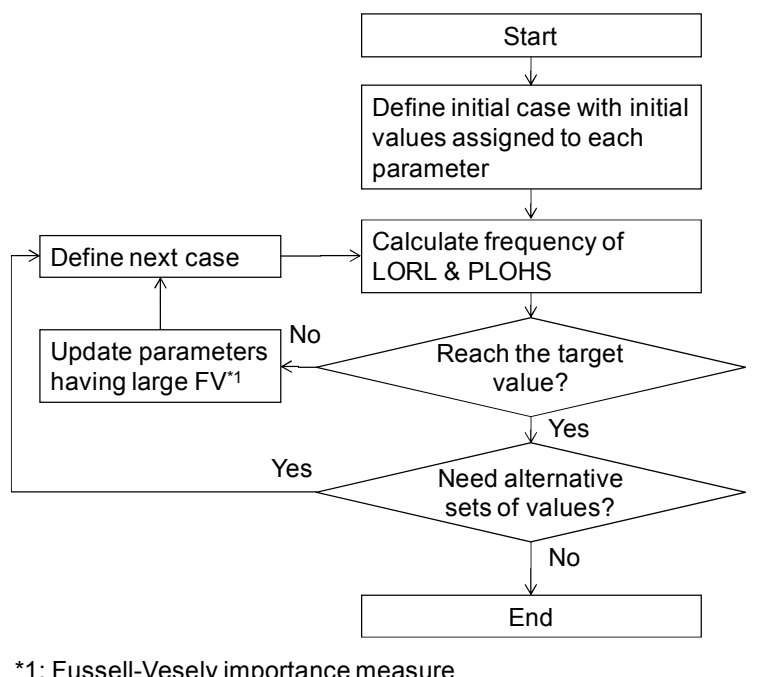

Fig. 8 Flow chart to obtain the candidates of target reliabilities

Table 3 Reliability parameters assumed in calculation of the LORL frequency and the calculation results

\begin{tabular}{|c|c|c|c|c|c|c|}
\hline Parameters & Events & Initial case & Case 1 & Case 2 & Case 3 & Case 4 \\
\hline \multirow{4}{*}{$\begin{array}{l}\text { Occurrence rate o } \\
\text { the event in a } \\
\text { single loop, } \\
\text { compartment, or } \\
\text { component (/year }\end{array}$} & Primary coolant boundary failure in the PHTS & $7.79 \times 10^{-4}$ & $5.0 \times 10^{-5}$ & $5.0 \times 10^{-6}$ & $2.5 \times 10^{-6}$ & $1.5 \times 10^{-6}$ \\
\hline & Primary coolant boundary failure of the reactor vessel & $2.85 \times 10^{-5}$ & $2.85 \times 10^{-5}$ & $2.0 \times 10^{-6}$ & $2.0 \times 10^{-6}$ & $2.0 \times 10^{-6}$ \\
\hline & $\begin{array}{l}\text { Boundary failure of the guard vessels/pipes constituting } \\
\text { representative compartment in the PHTS }\end{array}$ & $4.27 \times 10^{-4}$ & $1.0 \times 10^{-4}$ & $1.0 \times 10^{-5}$ & $1.0 \times 10^{-5}$ & $2.0 \times 10^{-5}$ \\
\hline & Boundary failure of the reactor guard vessel & $2.85 \times 10^{-5}$ & $2.85 \times 10^{-5}$ & $2.85 \times 10^{-5}$ & $2.0 \times 10^{-5}$ & $2.0 \times 10^{-5}$ \\
\hline \multicolumn{2}{|c|}{ LORL frequency in a single reactor(/year) } & $1.9 \times 10^{-4}$ & $1.8 \times 10^{-6}$ & $1.9 \times 10^{-8}$ & $9.6 \times 10^{-9}$ & $9.9 \times 10^{-9}$ \\
\hline \multirow{4}{*}{$\begin{array}{l}\text { Fussell-Vesely } \\
\text { importance } \\
\text { measure to the } \\
\text { LORL frequency }\end{array}$} & $\begin{array}{l}\text { Primary coolant boundary failure in the PHTS } \\
\end{array}$ & 0.996 & 0.851 & 0.748 & 0.597 & 0.491 \\
\hline & Primary coolant boundary failure of the reactor vessel & 0.031 & 0.336 & 0.377 & 0.528 & 0.582 \\
\hline & $\begin{array}{l}\text { Boundary failure of the guard vessels/pipes constituting } \\
\text { representative compartment in the PHTS }\end{array}$ & 0.196 & 0.425 & 0.374 & 0.440 & 0.606 \\
\hline & Boundary failure of the reactor guard vessel & 0.000 & 0.027 & 0.178 & 0.252 & 0.243 \\
\hline
\end{tabular}

Initial case has initial values determined by referring PSA instances.

Cases 1 to 4 are cases for parameter survey aiming at the target LORL frequency.

Table 4 Reliability parameters assumed in calculation of the PLOHS frequency and the calculation results

\begin{tabular}{|c|c|c|c|c|c|c|}
\hline Parameters & Events & Initial case & Case 1 & Case 2 & Case 3 & Case 4 \\
\hline \multirow{3}{*}{$\begin{array}{l}\text { Occurrence rate of the } \\
\text { event in a single loop } \\
\text { (/year) }\end{array}$} & Primary coolant boundary failure in the PHTS & $2.5 \times 10^{-6}$ & $2.5 \times 10^{-6}$ & $2.5 \times 10^{-6}$ & $2.5 \times 10^{-6}$ & $1.5 \times 10^{-6}$ \\
\hline & Secondary coolant boundary failure in the PRACS & $1.0 \times 10^{-3}$ & $1.0 \times 10^{-4}$ & $1.0 \times 10^{-5}$ & $3.5 \times 10^{-6}$ & $4.0 \times 10^{-6}$ \\
\hline & Secondary coolant boundary failure in the DRACS & $1.0 \times 10^{-3}$ & $1.0 \times 10^{-4}$ & $1.0 \times 10^{-5}$ & $3.5 \times 10^{-6}$ & $4.0 \times 10^{-6}$ \\
\hline \multicolumn{2}{|c|}{$\begin{array}{l}\text { PLOHS frequency in a single reactor(/year) } \\
\end{array}$} & $3.6 \times 10^{-4}$ & $3.7 \times 10^{-6}$ & $4.8 \times 10^{-8}$ & $8.6 \times 10^{-9}$ & $8.6 \times 10^{-9}$ \\
\hline \multirow{3}{*}{$\begin{array}{l}\text { Fussell-Vesely } \\
\text { importance measure to } \\
\text { the PLOHS frequency }\end{array}$} & $\begin{array}{c}\text { Primary coolant boundary failure in the PHTS } \\
\end{array}$ & 0.003 & 0.032 & 0.250 & 0.488 & 0.333 \\
\hline & Secondary coolant boundary failure in the PRACS & 0.998 & 0.984 & 0.875 & 0.756 & 0.833 \\
\hline & Secondary coolant boundary failure in the DRACS & 0.666 & 0.661 & 0.625 & 0.585 & 0.611 \\
\hline
\end{tabular}
$\begin{array}{llll}\text { the PLOHS frequency } & \text { Secondary coolant boundary failure in the DRACS } & 0.666 & 0.661\end{array}$

Initial case has initial values determined by referring PSA instances.

Cases 1 to 4 are cases for parameter survey aiming at the target LORL frequency.

The reliability parameters assumed in calculation of the PLOHS frequency and the calculation results are shown in Table 4. The Fussell-Vesely importance measure to the 
PLOHS frequency was also calculated as shown in Table 4. The reliability parameter values for cases 3 and 4 in Table 4 become candidates of the reliability target for the structures and components so as to suppress the PLOHS frequency not higher than $1 \times 10^{-8} / \mathrm{ry}$.

\section{Application of the seismic PSA analysis model}

\subsection{Seismic PSA analysis model}

The reliability target of the static structures and components against failure induced from an earthquake was examined by utilizing the seismic PSA analysis model developed for a preliminary evaluation of the JSFR. Figure 9 shows an example of the system event tree to identify the core damage sequences initiated from an earthquake with significantly large magnitude.

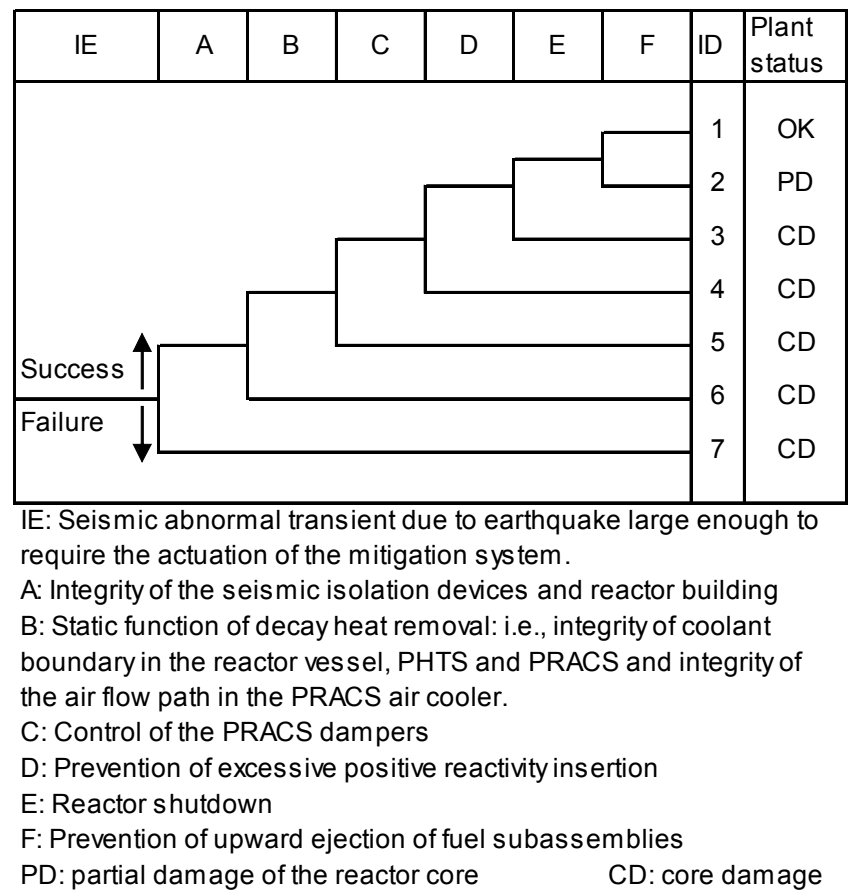

Fig. 9 An example of system event tree to identify seismic core damage sequences

This event tree includes six major event headings. The heading " $\mathrm{A}$ " represents a branch by success or failure of the supporting function of the seismic isolation device or the integrity of the reactor building. It is regarded that in case of failure in the heading " $\mathrm{A}$ " all the static structures and components constituting the reactor heat transport system and DHRS such as the reactor vessel supporting structure are failed with resulting in loss of core configuration. Obviously in this case heat removal function is lost. However, it is unclear whether this causes loss of reactor shutdown function.

The headings " $\mathrm{B}$ " and " $\mathrm{C}$ " are events representing the DHRS function. The heading " $\mathrm{B}$ " represents the static function required for decay heat removal, which consists of the PHTS flow path, the secondary sodium flow path and the air flow path at the air cooler in the PRACS. The heading "C" represents the dynamic function to control the natural air flow rate by controlling the damper opening at the air cooler in the PRACS.

The failure criterion of the DHRS in developing the seismic event tree is simplified with considering conservativeness: i.e., it is regarded that loss of natural circulation in at least two trains among all the three trains of the DHRS leads to loss of the DHRS function. If at least one train of the DHRS provides the forced air flow by the blower at the air cooler combined with natural circulation in the sodium circuit, the decay heat is successfully removed. However, we assume conservatively that the dynamic function of the blower and its electric power source would be lost in case of large earthquake to cause sodium 
boundary failures.

The PHTS and PRACS consist of two trains. It is thought that there is a strong correlation in a seismic response between those trains depending on the shaking direction because of the same vertical arrangement and horizontally symmetric arrangement. It is conservatively assumed that if a single train fails due to a seismic motion, the remained train also fails dependently.

In addition, when the coolant boundary of the reactor vessel and PHTS is damaged due to a strong seismic motion, their supporting function can be lost and the guard vessels/pipes can also lose their function at the same time due to similarity in seismic response or strength of the structures. It is conservatively assumed that if the reactor vessel or PHTS boundary fails due to a seismic motion, the guard vessel/pipe also fails dependently.

Based on the above consideration, it can be said that loss of the static DHRS function is the reactor vessel failure; or the sodium boundary failure in a single train of the PHTS or PRACS; or loss of the air flow path (i.e., air duct failure) of the air cooler in a single train of the PRACS.

As a result of the event tree development, seven sequences were obtained. Only the sequence 1 results in an intact reactor core. The sequence 2 could lead to partial damage of the reactor core. The sequence 2 also ends with keeping intact the systems for decay heat removal. In this sequence, even if some fuel subassemblies are damaged, their damage would terminate without propagation, and the radioactive materials would be contained inside the primary coolant boundary, as long as all the fuel subassemblies at the reactor core are cooled stably. In this case, integrity of the reactor containment would be maintained. In the sequences 3 and 4, the reactor core becomes damaged in a short time before the reactor shuts down. Under the core damage condition, the reactor containment would be maintained intact, as long as the degraded core is successfully retained and cooled in the reactor vessel. However, if such in-vessel retention fails, the containment would also lose its integrity. The probability estimation on their consequence is performed in the level-2 PSA. The other sequences 5 to 7 would lead to both the core damage and loss of the reactor containment at a conditional probability of 1 due to loss of heat removal function without depending on success/failure in the reactor shutdown.

\subsection{Derivation of the Reliability Target}

In order to examine the reliability target of structures and components associated with the integrity of the sodium cooling system, the heading events "A" and "B" were selected among from the heading events developed in the seismic system event tree. The seismic fragility and the seismic hazard should be evaluated in a mutually consistent manner based on the same site condition. At the present time, a site condition for the evaluation of the seismic hazard is not determined yet and the target for the seismic fragility cannot be determined based on the seismic hazard. Therefore, the reliability target of the structures and components for the seismic failure events was derived at a core damage sequence level.

According to Section 3.3 and Fig.1, the target values for the CDF and CFF due to seismic events would become $\sim 4.5 \times 10^{-7} / \mathrm{ry}$ and $\sim 4.5 \times 10^{-8} / \mathrm{ry}$, respectively. If we consider that the conditional containment failure probability becomes unity when the sequences 5 to 7 take place, a relationship between the sequence frequency and the target values for the $\mathrm{CDF}$ and CFF is expressed with equations (1) and (2).

$$
\begin{aligned}
& \mathrm{F}_{24}+\mathrm{F}_{57} \leq \sim 4.5 \times 10^{-7} / \mathrm{ry} \\
& \mathrm{F}_{24} \times \mathrm{P}_{\mathrm{CF}}+\mathrm{F}_{57} \leq \sim 4.5 \times 10^{-8} / \mathrm{ry}
\end{aligned}
$$

Where,

$\mathrm{F}_{24}$ : Sum of the occurrence frequency of sequences 2 to 4

$\mathrm{F}_{57}$ : Sum of the occurrence frequency of sequences 5 to 7 
$\mathrm{P}_{\mathrm{CF}}$ : Conditional containment failure probability when the sequences 2 to 4 take place.

The quantification result of $\mathrm{P}_{\mathrm{CF}}$ is obtained from the level-2 PSA. In this study, by assuming $\mathrm{P}_{\mathrm{CF}}=1$ as the most conservative case, the equations (1) and (2) are integrated into equation (3).

$\mathrm{F}_{24}+\mathrm{F}_{57} \leq \sim 4.5 \times 10^{-8} / \mathrm{ry}$

Regarding the distribution ratio of " $\mathrm{F}_{24}$ " and " $\mathrm{F}_{57}$ " in the equation (3), we can select the value that we want. If the target value is equally distributed to " $F_{24}$ " and " $F_{57}$ ", equations (4) and (5) are obtained.

$\mathrm{F}_{24} \leq \sim 2.3 \times 10^{-8} / \mathrm{ry}$

$\mathrm{F}_{57} \leq \sim 2.3 \times 10^{-8} /$ ry

It might not be realistic to require high reliability of dynamic function compared to that of static function against the earthquake. If the sequence 5 is separated from the others and if the target value of $\sim 1 \times 10^{-8} / \mathrm{ry}$ is assigned to the occurrence frequency of the sequence 5 , we obtain equations (6) and (7).

$\mathrm{F}_{5} \leq \sim 1 \times 10^{-8} / \mathrm{ry}$
$\mathrm{F}_{67} \leq \sim 1.3 \times 10^{-8} /$ ry

Where,

$\mathrm{F}_{5}$ : The occurrence frequency of sequence 5

$\mathrm{F}_{67}$ : Sum of the occurrence frequency of sequences 6 and 7.

The " $\mathrm{F}_{67}$ " indicates the occurrence frequency of failure in the heading events " $\mathrm{A}$ " and " $\mathrm{B}$ ". A candidate of the target value of " $\mathrm{F}_{67}$ ", which is our concern, is $\sim 1 \times 10^{-8} / \mathrm{ry}$.

\section{Conclusion}

The present research proposed a new method for determining the reliability target of structures and components in the SBC. In the new method, the reliability target is derived from the proposal to a quantitative safety goal that was published by the NSC of Japan and the quantitative safety design requirements on the CDF and the CFF that were determined in the FaCT project by JAEA, by utilizing PSA analysis models.

As a result of the examination on applicability of the new method, we confirmed that the present method combined with the PSA analysis model for internal initiating events is applicable to determination of the reliability target associated with a random failure of the structures and components, and we also confirmed that the method related to seismic initiating events can derive the target value of the occurrence frequency at which any of the important structures and components fails due to an earthquake.

\section{References}

(1) Asada, Y., Tashimo, M. and Ueta, M., System Based Code -Principal Concept-, Proc. 10th International Conference on Nuclear Engineering, Arlington, VA, USA, (2002), paper 22730.

(2) Asada, Y., Tashimo, M. and Ueta, M., System Based Code -Basic Structure-, Proc. 10th International Conference on Nuclear Engineering, Arlington, VA, USA, (2002), paper 22731.

(3) Asada, Y., Japanese Activities Concerning Nuclear Codes and Standards - Part II, Journal of Pressure Vessel Technology, ASME 128, 64, (2006).

(4) Asayama, T., Morishita, M., Dozaki, K. and Higuchi, M., Development of the System Based Code for Fast Breeder Reactors and Light Water Reactors - Basic scheme -, Proc. 10th International Conference on Nuclear Engineering, Arlington, VA, USA, (2002), paper 22725 .

(5) Asayama, T., Kawasaki, N., Morishita, N., Shibamoto, H. and Inoue, K., Balancing Material Selection and Inspection Requirements in Structural Design of Fast Breeder Reactors on "System Based Code" Concept, Nuclear Engineering and Design 238(2), 
(2008), pp.417-422.

(6) Special Committee on Safety Goals/Nuclear Safety Commission of Japan, Interim Report on Research and Deliberations on Safety Goals, (in Japanese) (2003).

(7) Kotake, S., Mihara, T., Kubo, S., Aoto, K., and Toda, M., Development of Advanced Loop-Type Fast Reactor in Japan (1): Current Status of JSFR Development, Proc. 2008 International Congress on Advances in Nuclear Power Plants, Anaheim, CA, USA, (2008), paper 8226.

(8) IPSN, A Probabilistic Safety Assessment of the Standard French 900 MWe Pressurized Water Reactor - Main Report-, (1990).

(9) Kurisaka, K., Probabilistic Safety Assessment of Japanese Sodium-cooled Fast Reactor in Conceptual Design Stage, Proc. 15th Pacific Basin Nuclear Conf., Sydney, Australia, (2006), paper 326

(10) Lambert, H. E., Measures of Importance of Events and Cut Sets in Fault Trees, UCRL-75853, Lawrence Livermore Laboratory, (1974). 